MATEC Web of Conferences 19, 01003 (2014)

DOI: $10.1051 /$ matecconf/ 20141901003

(C) Owned by the authors, published by EDP Sciences, 2014

\title{
Experimental study of convective flows in the freezer
}

\author{
Alexander Krasnoshlykov, Vyacheslav I. Maksimov \\ Institute of Power Engineering, Tomsk Polytechnic University, Tomsk 634050, Russia
}

\begin{abstract}
The article discusses an experimental study of convective heat transfer in the amount of air and water in the freezer, under various operating conditions of the refrigeration unit.
\end{abstract}

The system by which a refrigerator removes heat from the freezer and refrigeration compartments and disposes of it outside your unit relies on the concept of convection. Convection is the process of heat transfer through the movement of matter, usually a gas or a liquid. In a refrigerator, convection occurs through the use of refrigerant gases and a compressor.

The principle of convection is reliant on the circulating air, which transfers heat to the food as it moves around the food. A refrigerator uses copper tubes filled with refrigerant coolant to do the same job as the air in a convection oven.

In a modern refrigerator, the refrigerant used in the copper coils is called tetrafluoroethane, specifically the gas R-134A. Refrigerants are gases that are stable and can be compressed and expanded, allowing for the absorption and discharge of heat. Most importantly, when a refrigerant gas is compressed, it can be heated to a higher temperature than when it is expanded.

Refrigerators operate using convection by circulating the gas through the copper lines inside of the refrigerator or freezer compartment. The lines, and the gas contained within them, absorb the heat contained in the refrigerator and freezer compartments, and are circulated back outside of the unit. The unit then compresses the refrigerant gas, using a compressor, outside of the refrigerator. As the gas is compressed, it discharges the heat it absorbed inside of the food compartments into the room.

In addition to heat, as a byproduct of the refrigeration process, waste water is created. This is because of the humidity in the air condensing on the racks and walls inside the refrigerator and freezer, and on the refrigerant coils. This waste water is drained beneath the refrigerator into a drain pan. The drain pan is located near the fan and compressor, and uses the heat from these components to aid in evaporation $[1,2]$.

The boundary-value problem of conjugate convective-conductive non-steady heat transfer for the domain describing a profile of a typical heat supply object is considered. The temperature fields' comparison with the data of the experiment is analysed. It is also proved that the heat transmission presents a three-dimensional process, the modeling of which on the basis of a plain model leads to considerable deviations according to the values of typical temperatures [3, 4].

The purpose of this work is the experimental determination of the values of temperature in the freezer refrigeration equipments under natural convection and the presence of different thermal load.

To achieve this objective, the following tasks:

- Development of methodology of the experiment;

- Creation of experimental stand;

- Experimental studies;

This is an Open Access article distributed under the terms of the Creative Commons Attribution License 4.0, which permits unrestricted use, distribution, and reproduction in any medium, provided the original work is properly cited. 
- Analysis of the results.

The experimental equipment is a heat exchanger freezer (Figure 1), and consists of a compressor with a rated voltage of $220 \mathrm{~V}$ and a current of $0.8 \mathrm{~A}$, after the compressor is a condenser heat exchanger for the heat output of the heat exchanger the working fluid into the environment (natural cooling).

Next is the filter-drier. One of the basic element is a capillary tube heat exchanger. The evaporator is located directly in the freezer. Also the system is provided with a pressure gauge for detecting the pressure in the condenser and evaporator. Working fluid heat exchanger is refrigerant R-134A.

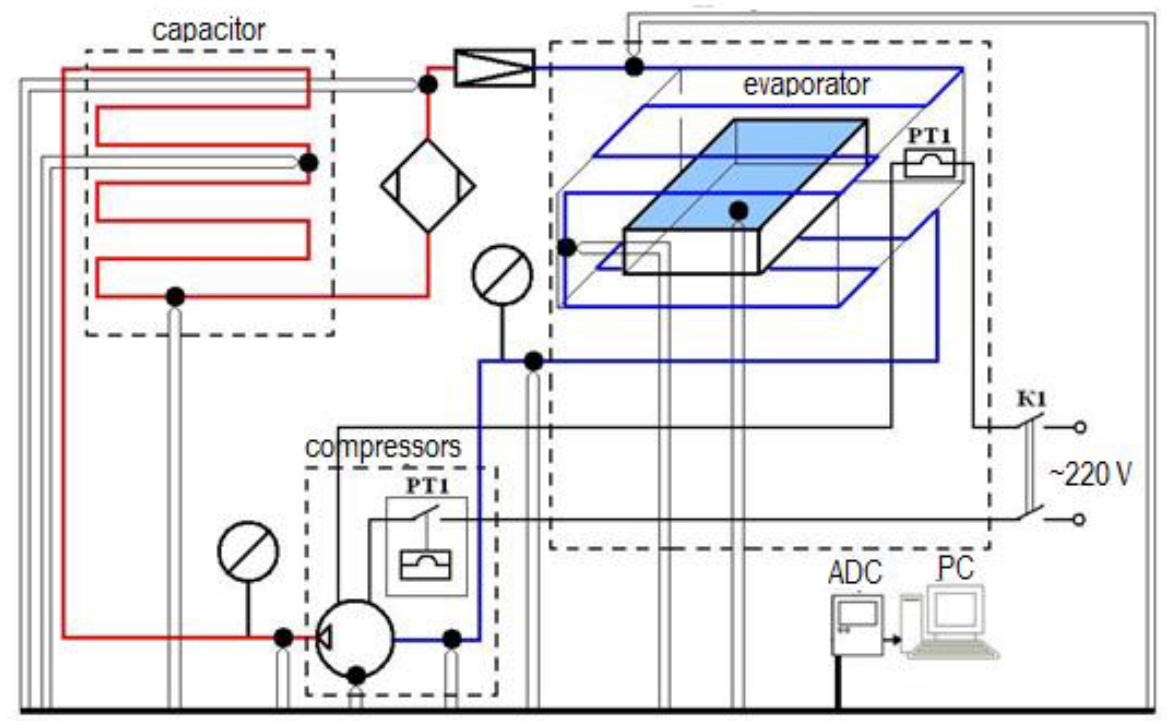

Figure 1. Schematic representation of the laboratory setup.

When planning the experiment number of experiments $n=6$ and the numerical values of the major factors such as ambient temperature $\mathrm{T}_{\mathrm{a}}=20^{\circ}, \mathrm{C}$; water temperature in the container $\mathrm{T}_{\mathrm{w}}=25^{\circ}, \mathrm{C}$; Position parameters of the heat exchange was selected. The experiment was conducted under conditions allowing the control of the numerical values of all major factors. The experiment was conducted with a freezer compartment having the following dimensions of the coordinates $X, Y, Z$ : $(0,5 \times 0,35 \times 0,25)$ $\mathrm{m}$. A series of experiments on the freezing $150 \mathrm{ml}$ and $3000 \mathrm{ml}$ of water, placed in the center of the freezer compartment. Two variants of the installation conditions: 1 - container placed in the freezer since the start work of the freezer; 2 - a container of water placed in the freezer after steady state operation are used. In the experiments the temperature was obtained by thermocouple 11 at equal intervals.

Thermocouples are placed in the following locations:

1. After the compressor;

2. In the middle part of the condenser;

3. At the end of the capacitor;

4. Before the capillary tube;

5. The initial part of the evaporator;

6. In the middle of the evaporator;

7. After the evaporator;

8. Before compressor;

9. Compressor;

10. Directly in the volume of water;

11. In the cooling chamber; 
Temperature measurement in the study area was carried out using 14 thermocouples. Of which seven thermocouples measured the temperature of the air within the chamber section with a variable $X$ coordinate and $\mathrm{Y}$ at constant $\mathrm{Z}$ (Table 1). Other 7 - measured temperature of the water in the container. Experimental study was conducted with the change of coordinate Z. Coordinates X and Y remain constant (Table 2). Schematic layout of thermocouples are shown in Figure 2.

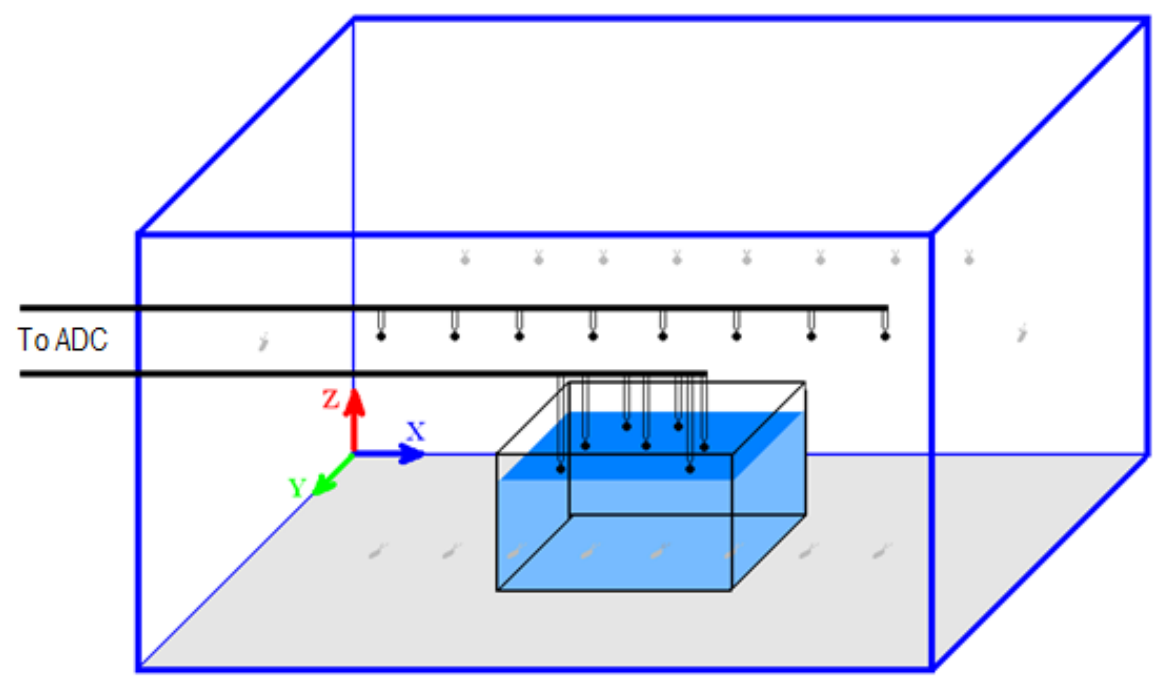

Figure 2. Schematic representation of the study area.

Table 1- Description of the thermocouples arrangement in the volume of air

\begin{tabular}{|l|l|l|l|l|l|l|l|}
\hline & 1 & 2 & 3 & 4 & 5 & 6 & 7 \\
\hline $\mathrm{X}, \mathrm{M}$ & 0,06 & 0,12 & 0,18 & 0,24 & 0,30 & 0,36 & 0,42 \\
\hline $\mathrm{Y}, \mathrm{M}$ & 0,17 & 0,17 & 0,17 & 0,17 & 0,17 & 0,17 & 0,17 \\
\hline $\mathrm{Z}, \mathrm{m}$ & 0,12 & 0,12 & 0,12 & 0,12 & 0,12 & 0,12 & 0,12 \\
\hline
\end{tabular}

Table 2 - Description of the thermocouples arrangement in the volume of water

\begin{tabular}{|l|l|l|l|l|l|l|l|}
\hline & 1 & 2 & 3 & 4 & 5 & 6 & 7 \\
\hline $\mathrm{X}, \mathrm{M}$ & 0,15 & 0,07 & 0,22 & 0,05 & 0,22 & 0,11 & 0,15 \\
\hline $\mathrm{Y}, \mathrm{M}$ & 0,11 & 0,11 & 0,15 & 0,18 & 0,11 & 0,05 & 0,15 \\
\hline \multirow{3}{*}{$\mathrm{Z}, \mathrm{M}$} & 0,$015 ;$ & 0,$015 ;$ & 0,$015 ;$ & 0,$015 ;$ & 0,$015 ;$ & 0,$015 ;$ & 0,$015 ;$ \\
& 0,$05 ;$ & 0,$05 ;$ & 0,$05 ;$ & 0,$05 ;$ & 0,$05 ;$ & 0,$05 ;$ & 0,$05 ;$ \\
& $0,07$. & $0,07$. & $0,07$. & $0,07$. & $0,07$. & $0,07$. & $0,07$. \\
\hline
\end{tabular}

In Figure 3 is a graphical representation of the temperature of water $(3000 \mathrm{ml})$ over time of the refrigeration plant. These temperature values on the chart were taken through seven thermocouples located in the cross section of $0.05 \mathrm{~m}$ (average section). In this case, given the values obtained in the first mode of the unit when the water container was placed in the freezer from the moment the installation. As can be seen from the plots, the phase transition duration is 7.5 hours. At the point when the temperature reaches $0^{0}$, the water in the vessel begins the phase transition. 


\section{MATEC Web of Conferences}

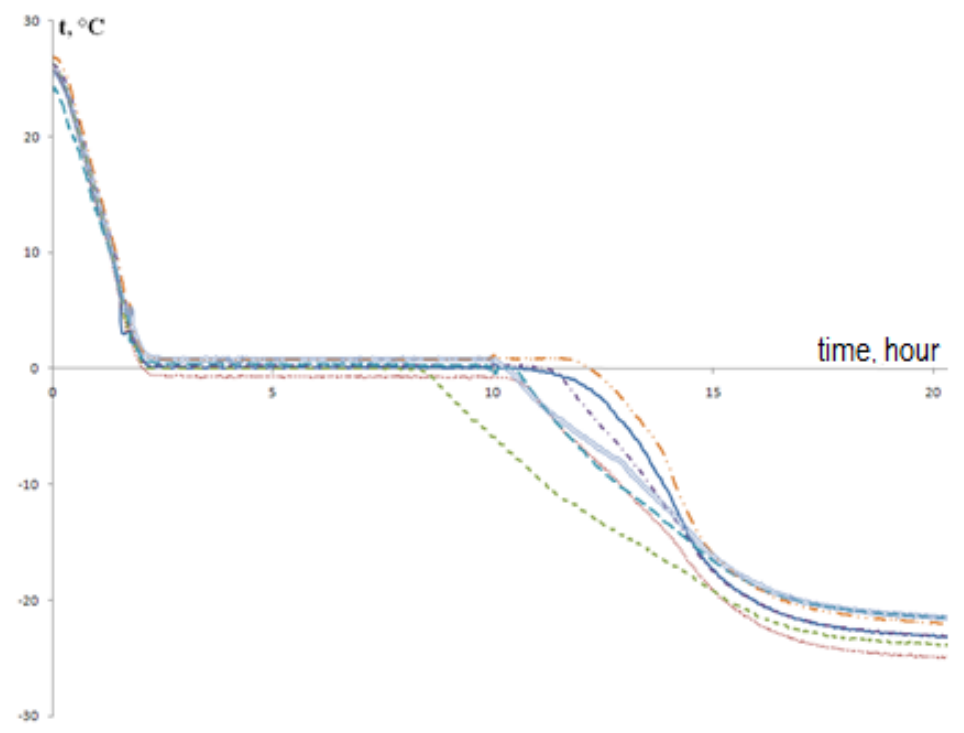

Figure 3. Change in water temperature in the section $Z=0,05 \mathrm{~m}$

$$
-1 \text { thermocouple; ........ } 2 \text { thermocouple; _ _ _. - } 3 \text { thermocouple; }
$$

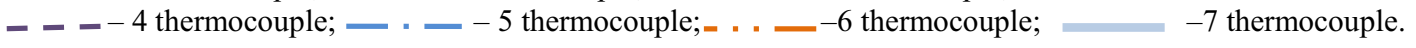

Figure 4 shows graphs of Lowering the temperature of the initial temperature to $0^{\circ} \mathrm{C}$. On these curves clearly visible region of the temperature perturbation $\sim 4^{0} \mathrm{C}$. This is because the water at $4^{0}, \mathrm{C}$ has a maximum density. As can be seen from the graphs, this leads to the intensification and changing nature of convective flows in the volume of water.

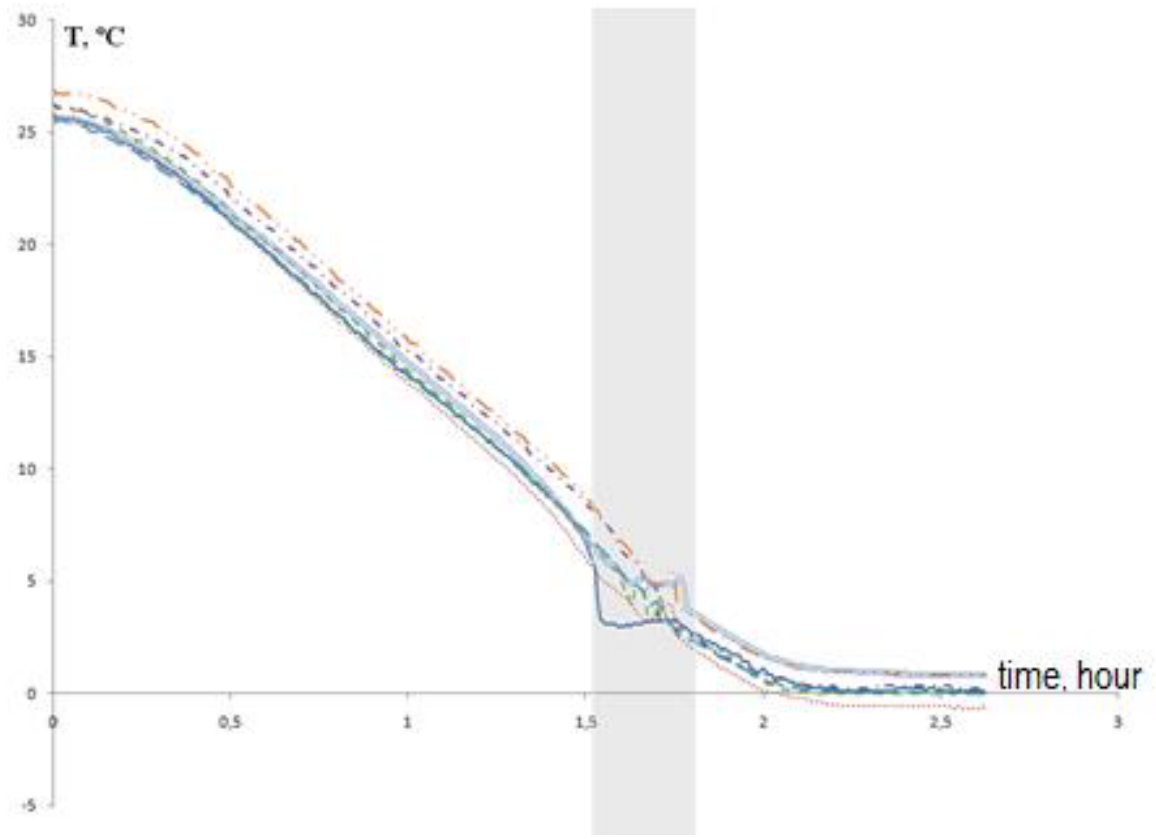

Figure 4. Change in water temperature versus time in a section of the installation $Z=0,05 \mathrm{~m}$

-1 thermocouple; ........ -2 thermocouple; $\_-1-3$ thermocouple;

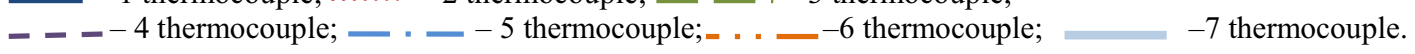

Figure 5 shows a portion of the air temperature in the freezer before the first compressor is turned off by the thermal relay. On this chart, so you can see where the temperature perturbation at time 1-1.5 
hrs This can occur for two reasons: 1-displacement phase transition front freon of freezer; 2emergence at this time in the water the temperature perturbation $4^{0}, \mathrm{C}$ leads to temperature changes in the volume of air.

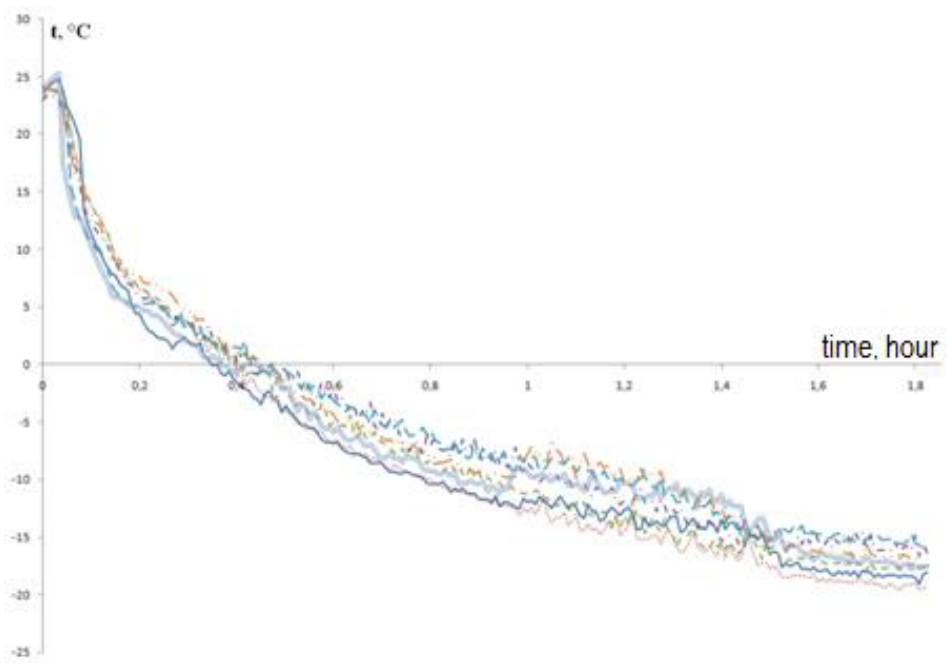

Figure 5. Changes in air temperature in the freezer.

-1 thermocouple; ........ - 2 thermocouple; _ _ _ - -3 thermocouple;

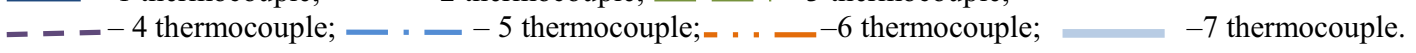

As the main results and conclusions values of temperature freezer at different heat load and different operating conditions of the freezer were obtained; It was revealed that convective flows is changed after decreasing temperature. It is established that during operation of freezer in the presence of thermal load arises chamber temperature values heterogeneity in different areas of the freezing chamber. It was found the heterogeneity associated with the presence of intense convective flows of air and coolant in the test chamber; Found that different operating conditions of the refrigeration unit in the presence of a small amount of thermal load (less than $200 \mathrm{ml}$ ) did not significantly influence the rate of freezing liquid products. It was revealed the discrepancy between the times of freezing at different modes product was not more than $11.3 \%$;

Work performed under the research state assignment "Science" (Code of Federal Target Scientific and Technical Program 2.1321.2014)

\section{References}

1. G.V. Kuznetsov, V.I. Maksimov, M.A. Sheremet, Journal of Applied Mechanics and Technical Physics, 588-595 (2013).

2. V.I. Maksimov, D.A. Nagornov, EPJ Web of Conferences, 4 (2014).

3. G.V. Kuznetsov, V.I. Maksimov, Journal of Engineering Thermophysics, 270-275 (2007)

4. Vladimír Gerlich, Kateřina Sulovská, Martin Zálešák, Measurement, 2003-2012 (2013) 